\title{
A/C Energy Management and Vehicle Cabin Thermal Comfort Control
}

\author{
Xingda Yan, James Fleming and Roberto Lot
}

\begin{abstract}
This paper introduces a novel multi-objective controller which regulates $\mathrm{A} / \mathrm{C}$ system operation in a trade-off between vehicle cabin comfort and fuel consumption for a conventional vehicle with internal combustion engine. The controller has been developed and tested in a simulated environment, where an energy-based model of the $\mathrm{A} / \mathrm{C}$ system is combined with a thermal dynamic model of the cabin which considers heat transfer to the environment. The control algorithm proposed herein is compared with two widely used control techniques in the industry, respectively the thermostat and PI control, under different driving cycles. This novel method is implementable in real-time, and simulation results show a reduction of up to $2 \%$ in $\mathrm{A} / \mathrm{C}$ system fuel consumption compared to existing methods with similar thermal performance.
\end{abstract}

Index Terms-A/C system modelling, Thermal comfort

\section{INTRODUCTION}

For a modern vehicle, the air conditioning (A/C) system is typically the ancillary system with the largest fuel consumption, and has a significant impact on the fuel efficiency of the vehicle [1]. An increment of 5\% in A/C system efficiency could potentially save more than 1.32 billion litres of fuel per year in the USA, according to a study by the US National Renewable Energy Laboratory [2].

Generally, the control techniques which are used to control the A/C system can be summarized as: (1) thermostat control, which is the mostly commonly used [3]; (2) PID control; (3) fuzzy logic based control; (4) optimization-based control. Research attention has been mainly placed on improving steady-state performance due to the temperature oscillation around the set-point [4] and reducing the energy consumption and the mechanical component wear due to the frequency of ON/OFF actions [5]. In order to further improve steady-state performance [6], another widely used control technique for the $\mathrm{A} / \mathrm{C}$ system is PID control. One of the major challenges of controlling $\mathrm{A} / \mathrm{C}$ systems is the nonlinearity and uncertainty in A/C processes [7] Fuzzy logic based control control techniques have been utilized to deal with these issues. Khayyam et al. [8] described a intelligent energy management system to reduce the energy consumption of $\mathrm{A} / \mathrm{C}$, which includes three fuzzy controllers. Frazaneh et al. [9] focuses on thermal comfort temperature and energy. They use Fanger's predicted mean vote as controller feedback, and evaporator cooling capacity is selected as a criterion for energy consumption. Two fuzzy controllers are designed, one with a temperature feedback and the other with the predicted mean value index

Xingda Yan, James Fleming and Roberto Lot are with the Mechanical Engineering Department, Faculty of Engineering and the Environment, University of Southampton, Southampton, UK, SO17 1BJ e-mail: X.Yan@soton.ac.uk . feedback. The main disadvantage of these fuzzy logic based control scheme is that a large amount of experimental data is required for model training, which should cover the whole operating range. In recent years, some research effort has been spent on optimization-based control design for the $\mathrm{A} / \mathrm{C}$ system to achieve a tradeoff between fuel consumption, cabin comfort and system durability [10]. However, the possibility of implementation of these optimization-based controllers is unknown due to the high computation burden of solving optimal control problems in realtime.

Therefore, it is still a open question how to design an A/C system controller for a conventional vehicle which considers both thermal performance and energy efficiency, yet can be implemented at low cost and low effort.

In this paper, a multi-objective control strategy which can make a trade-off between cabin comfort and the fuel consumption is presented for a conventional vehicle with internal combustion engine. Fanger's predicted mean vote (PMV) is used as the main control target, which is explained in section II. In section III, the energy-based model of the A/C system proposed by Zhang et al. [10] is adopted and combined with a thermal dynamic model of the cabin with consideration of the heat transfer with the environment and the powertrain model . In section IV, a multi objective controller is formulated which takes into account both cabin comfort and instantaneous engine efficiency. By incorporating a stored map of engine efficiency, the control law can encourage $\mathrm{A} / \mathrm{C}$ system work when the system efficiency is high and discourage $\mathrm{A} / \mathrm{C}$ system work when the system efficiency is low. The performance of the proposed control law is compared with two widely used $\mathrm{A} / \mathrm{C}$ system control techniques in the industry: thermostat control and PI control. Simulation results in section V indicate that the proposed law can make a compromise between cabin comfort and fuel efficiency. It should be stressed that implementation of the proposed method does not require estimation of the parameters of the complex A/C system model. The implementation of the proposed method is straightforward, requiring only a table lookup and calculation of a single additional term compared to existing PI controllers.

\section{Thermal COMForT}

Thermal comfort in the vehicle is usually evaluated using the air temperature in the cabin and the mean radiant temperature. In accordance with the ASHRAE 55 [11] international standards, thermal comfort can be defined as "the condition of mind which expresses satisfaction with the thermal environment", illustrating that it is a cognitive 
process influenced by various quantities, physical activity, physiological and psychological factors. The two most widely used thermal comfort indexes: Predicted Mean Vote (PMV) and Predicted Percentage of Dissatisfied (PPD), both of which were developed by Fanger [12] are adopted in this paper. For simplicity, the details of the calculation of PMV is omitted here. In general, the PMV is a empirical function of several parameters as follow.

$$
P M V=f\left(P_{m e t}, I_{c l}, T_{c}, T_{r}, T_{c l}, v_{a}, p_{a}\right)
$$

where $I_{c l}$ is the clothing insulation, $T_{r}$ is the mean radiant temperature, $T_{c l}$ is the clothing surface temperature, $v_{a}$ is the air velocity and $p_{a}$ is the water vapor partial pressure. The recommended acceptable PMV range for thermal comfort from ASHRAE 55 is between -0.5 and +0.5 for an interior space.

The associated PPD index is a function of the PMV index:

$$
P P D=100-95 e^{\left[-\left(0.3353 P M V^{4}+0.2179 P M V^{2}\right)\right]}
$$

From the concept of thermal comfort, people will hardly notice the temperature change if the thermal comfort is maintained within a neutral zone. In practice, the closed environment is considered as comfortable if the PMV is between -0.5 and +0.5 [12]. For convenience, the mean PPD value is used to indicate the mean discomfort in the cabin during the whole simulation. The reason to use PPD instead of PMV is that the PPD is a unsigned value which represents the discomfort caused by hot and cold in the same way, while PMV is a signed value which has a different sign for hot and cold sensations.

\section{A/C AND Vehicle Models}

This section describes the mathematical model which has been used to develop and test the new A/C control algorithms. In order to take into account both cabin thermal comfort and fuel consumption, three models are combined which characterize the power flow among three different subsystems: the cabin, the A/C system, and the vehicle powertrain. Moreover, a model of driving power losses is included as it has major influence on the power-train efficiency.

In this paper, a typical car air conditioning system with refrigerant R134A is considered, which contains four main components: compressor, condenser, evaporator and expansion valve. According to the thermodynamic property of R134A [13], when the refrigerant pressures $p_{1}$ and $p_{2}$ in the condenser and evaporator are given, the enthalpy of the four vertices $(1,2,3,4)$ can be calculated under the assumption that $h_{3}=$ $h_{4}$, which are equal to the saturated liquid enthalpy at the condenser pressure $p_{1}$, and the refrigerant temperature out of the evaporator is superheated by $10^{\circ} \mathrm{C}$.

\section{A. Compressor and Heat Exchangers}

The compressor is connected to and disconnected from the crankshaft via a magnetic clutch. The mass flow rate of the refrigerant circulating in the system is determined by the engine speed $\omega_{e}$. The quasi-static model proposed in [10] is summarised below.

$$
\begin{aligned}
& \dot{m}_{c}=\eta_{v} V_{d} \rho_{1} \omega_{e} h_{2}=h_{1}+h_{1}\left(\left(\frac{p_{2}}{p_{1}}\right)^{\frac{\gamma-1}{\gamma}}-1\right) \frac{1}{\eta_{s}} \\
& P_{c}=\dot{m}_{c}\left(h_{2}-h_{1}\right) \quad \tau_{c}=\frac{P_{c}}{\omega_{e}} \quad C O P=\frac{P_{c}}{\omega_{e} \tau_{c}}
\end{aligned}
$$

Here, $\dot{m}_{c}$ is the mass flow rate of the refrigerant R134A, $P_{c}$ is power consumption of the compressor, $\tau_{c}$ is the torque demand for the compressor, $C O P$ is the coefficient of Performance, $\rho_{1}$ is the saturated vapour density under pressure $p_{1}, \gamma$ is the specific heat ratio of $\mathrm{R} 134 \mathrm{~A}$ and $V_{d}, \eta_{v}, \eta_{s}$ are the displacement, volumetric efficiency and isentropic efficiency respectively for a specific compressor model.

The energy-based condenser and evaporator model can be expressed in the following form.

$$
\begin{aligned}
& \dot{p_{1}}=\frac{\dot{m}_{a, e} c_{a}\left(T_{a, \text { in }, e}-T_{a, \text { out }, e}\right)+\dot{m}_{c}\left(h_{4}-h_{1}\right) * \sigma}{d_{1}\left(p_{1}\right)} \\
& \dot{p_{2}}=\frac{\dot{m}_{a, c} c_{a}\left(T_{a, \text { in }, c}-T_{a, \text { out }, c}\right)+\dot{m}_{c}\left(h_{2}-h_{3}\right) * \sigma}{d_{2}\left(p_{2}\right)}
\end{aligned}
$$

where $\sigma$ is the compressor clutch signal, $\dot{m}_{a, e}, \dot{m}_{a, c}$ are the mass flow rates of air cross flowing through the evaporator and condenser respectively, The term $d_{1}$ and $d_{2}$ are the same function dependent on the refrigerant pressures in the evaporator and condenser with the subscript $(e, c)$ indicated the different heat exchanger. The reader is directed to [10] for further details.

\section{B. Cabin Thermal}

The purpose of the $\mathrm{A} / \mathrm{C}$ is maintaining a comfortable temperature inside the cabin. Hence, a model of the cabin temperature is necessary. For simplicity, the cabin is treated as a control volume with various energy loads. The model can be established based on energy balance as follows,

$$
\frac{d T_{c}}{d t}=\frac{1}{\rho_{a} V_{c a} c_{a}}\left(P_{M e t}+P_{R a d}+P_{A m b}+P_{A C}\right),
$$

where $T_{c}$ is the cabin temperature, $\rho_{a}$ is the air density, $V_{c a}$ is the cabin volume, and $c_{a}$ is the specific heat. Four major energy loads are considered: the metabolic load from the passengers $P_{M e t}$, the solar radiation load $P_{R a d}$ and ambient load caused by heat exchanging with the ambient air outside the cabin $P_{A m b} . P_{A C}$ is the cooling load from the A/C. The four loads may be calculated as,

$$
\begin{aligned}
P_{M e t} & =N P_{M s} & P_{R a d} & =A S_{c} e^{\left(-E_{c} \sec \theta_{z}\right)} \\
P_{A m b} & =h_{c} A\left(T_{A m b}-T_{c}\right) & P_{A C} & =\dot{m}_{a, b} c_{a}\left(T_{a, \text { out }, e}-T_{c}\right) .
\end{aligned}
$$

where $N$ is the number of passengers, $P_{M s}$ is the metabolic load for single passenger, which is about $100 \mathrm{~W}$ on average, $m_{a, b}$ is the mass flow rate of air out of the blower, $T_{A m b}$ is the ambient temperature, and $h_{c}$ is the heat transfer coefficient. For the calculation of solar radiation [14], $A$ is the car surface area, $S_{c}$ is the apparent solar irradiation, $E_{c}$ is the extinction coefficient and $\theta$ is the Zenith angle. 


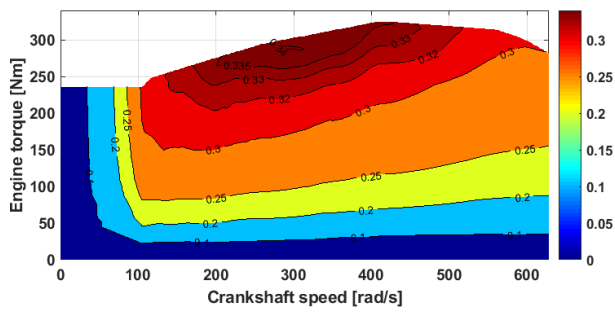

Figure 1: Engine efficiency map for the IC engine

\section{Powertrain and Driving Losses}

For the powertrain, a traditional passenger car is considered with a internal combustion engine and an automatic transmission. The internal combustion engine model is implemented as a lookup table [15] that maps engine torque and crankshaft speed values to the engine efficiency as shown in Fig. 1 . Hence we may consider the model as consisting of a single mathematical function

$$
\dot{m}_{f}=f\left(\tau_{e}+\tau_{c}, \omega_{e}\right)
$$

where $\dot{m}_{f}$ is the rate of change of fuel mass in the fuel tank of the vehicle, $\tau_{e}$ is the crankshaft torque in order to power the wheel, $\omega_{e}$ is the angular velocity of the crankshaft. The crankshaft torque $\tau_{e}$ and speed $\omega_{e}$ are obtained from the powertrain model which consists of the transmission model and the vehicle motion model. The relationship of the torque and angular velocity before and after the gearbox is,

$$
\tau_{w}=N_{g} \tau_{e} \quad \omega_{e}=\omega_{w} N_{g},
$$

where $\tau_{w}$ is the torque delivered to the wheel, $\omega_{w}$ is the angular velocity of the wheel and $N_{g}$ is the gear ratios.

The vehicle is taken as a mass obeying Newton's second law, so that the vehicle motion can be modelled as

$$
m \dot{v}=\frac{\tau_{w}+\tau_{h}}{r}-\frac{1}{2} \rho A_{f} C_{d} v^{2}-C_{r r} m g-m g \sin \theta
$$

where $m$ is the vehicle mass, $v$ the vehicle speed, $F_{D}$ the traction force, $F_{A}$ the aerodynamic resistance force, $F_{R}$ the rolling friction force, $\tau_{h}$ the mechanical braking torque, $r$ the wheel radius, $\rho$ the air density, $A_{f}$ the frontal area, $C_{d}$ the coefficient of drag and $C_{r r}$ the coefficient of rolling resistance, $\theta$ is the road gradient.

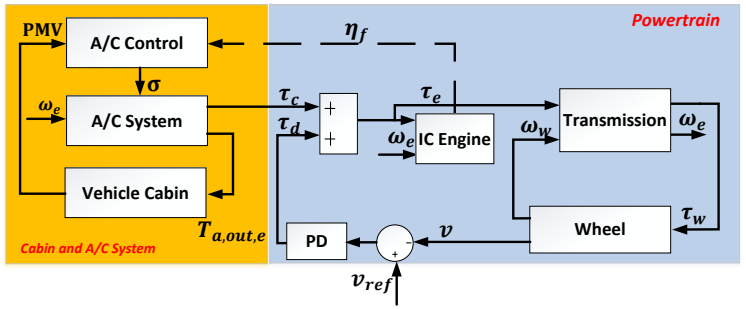

Figure 2: Control diagram of the whole system

\section{Controller Design}

Firstly, the proposed control structure for the simulation, which is shown in Fig. 2 is described. There are two inputs for the A/C system, which are the switching signal of the compressor clutch $\sigma$ and the engine speed $\omega_{e}$. However, the engine speed $\omega_{e}$ is the output of the transmission and depends on the drive cycle, and therefore the switching signal $\sigma$ is the only control variable. The cabin comfort index PMV is one of the inputs for the $\mathrm{A} / \mathrm{C}$ controller. In some control algorithms considered below, the engine efficiency $\eta_{e}$ is also an input for the controller. The vehicle powertrain is controlled to track a desired vehicle speed profile $v_{\text {ref }}$ by a PD controller. The output of the PD controller is the powertrain torque demand $\tau_{d}$. And the $\mathrm{A} / \mathrm{C}$ system torque $\tau_{c}$ will be controlled in order to maximise thermal comfort and minimise fuel consumption as discussed in the following sections.

\section{A. Thermostat Controller}

The A/C system switches from OFF to ON when the cabin temperature exceeds the desired temperature $T_{S E T}$ by more than a threshold $T_{h}$, and it switches from ON to OFF when the cabin temperature is lower than the desired temperature $T_{S E T}$ by $T_{h}$. Hence, the thermostat controller can be defined as,

$$
\sigma=\left\{\begin{array}{l}
0 \rightarrow 1: \text { if } T_{c}-T_{S E T}>T_{h} \\
1 \rightarrow 0: \quad \text { if } T_{S E T}-T_{c}>T_{h}
\end{array}\right.
$$

where $T_{S E T}$ is the desired cabin temperature in the cabin, and $T_{h}$ is the temperature difference threshold.

\section{B. PI Controller}

The obvious benefit of using thermostatic control is that the rules directly relate to the ON/OFF of the A/C system. However, due to the discrete nature of the switching signal $\sigma$, it is troublesome to apply control theory developed for continuous models, such as PI controllers. Hence, the Pulse Width Modulation (PWM) technique, which is widely used in communication technology and power electronics control is adopted here to convert the switching signal to a so-called "duty cycle" $D$, which represents the fraction of the ON time period of the A/C system for a fixed switching frequency [16].

With the help of the PWM technique, a PI controller can be used to regulate the cabin comfort index $P M V$ to the desired value $P M V_{\text {ref }}$, which should be zero. Hence, the duty cycle can be calculated as

$$
\begin{aligned}
D_{P I} & =K_{p}\left(P M V(t)-P M V_{\text {ref }}\right) \\
& +K_{i} \int_{0}^{t}\left(P M V(s)-P M V_{r e f}\right) d s .
\end{aligned}
$$

where $K_{p}$ and $K_{i}$ is the coefficient of the PI controller.

\section{Multi-objective Controller including Cabin Comfort and Overall Efficiency}

In order to make a trade-off between the cabin comfort and fuel consumption, this proposed multi-objective controller can not only regulate the cabin comfort index $P M V$ to the reference $P M V_{\text {ref }}$, but may be modified to adjust the operation of $\mathrm{A} / \mathrm{C}$ system based on the overall efficiency of the cooling system, which corresponds to the product by the coefficient of performance of the $\mathrm{A} / \mathrm{C}$ system efficiency $C O P$ 
and engine efficiency $\eta_{e}$. An extra term $K_{e}\left(\eta_{e} C O P-\eta_{t}\right)$ is included in the controller: when the overall efficiency $\eta_{e} C O P$ is greater than the threshold $\eta_{t}$, this term is positive and encourages the A/C usage; when the overall efficiency $\eta_{e} C O P$ is less than the threshold $\eta_{t}$, the term is negative and discourages $\mathrm{A} / \mathrm{C}$ usage. The duty cycle function is defined as follows:

$$
\begin{aligned}
D & =K_{p}\left(P M V(t)-P M V_{\text {ref }}\right)+K_{e}\left(\eta_{e} C O P-\eta_{t}\right) \\
& +K_{i} \int_{0}^{t}\left(P M V(s)-P M V_{\text {ref }}\right) d s
\end{aligned}
$$

\section{Multi-objective Controller including Cabin Comfort and Engine Efficiency}

The major drawback of the multi-objective controller (8) defined above is that the calculation of $C O P$ instantaneously is not a trivial task, which makes this method difficult to implement in practice. Therefore, in this section, the proposed controller is simplified by only including the engine efficiency $\eta_{e}$ as

$$
\begin{aligned}
\bar{D} & =K_{p}\left(P M V(t)-P M V_{\text {ref }}\right)+K_{e}\left(\eta_{e}-\bar{\eta}_{t}\right) \\
& +K_{i} \int_{0}^{t}\left(P M V(s)-P M V_{\text {ref }}\right) d s
\end{aligned}
$$

where $\bar{\eta}_{t}$ is the efficiency threshold for this controller. The engine efficiency $\eta_{e}$ can be calculated by a stored map with two inputs: the engine speed $\omega_{e}$ and the crankshaft torque $\tau_{e}$ as shown in Fig. 11. As $\omega_{e}$ and $\tau_{e}$ can be obtained from the vehicle ECU, the controller can be implemented without any additional sensors than the PI controller (7) and it is only necessary to store a look-up table for the engine efficiency map. Moreover, simulations will show that the performance of the proposed controller $[9]$ is very close to that of the more complex multi-objective controller (8).

\section{Simulation Results}

\section{A. A/C System Performance Under Different Control Schemes}

In this subsection, the vehicle speed is controlled to track the WLTP driving cycle [17], which includes a combination of urban, rural and highway driving. At the same time, the $\mathrm{A} / \mathrm{C}$ system is controlled by the four different control strategies: the thermostat controller (6), PI controller (7) which tracks thermal comfort only, the multi-objective controller (8) which takes into account the overall efficiency of the engine and $\mathrm{A} / \mathrm{C}$ system, and the multi-objective controller (9) which includes only engine efficiency without considering the COP of the $\mathrm{A} / \mathrm{C}$. For simplicity, it is assumed that the solar radiation is constant during the simulation as well as the mass flow rate of air out of the $\mathrm{A} / \mathrm{C}$ system.

1) Fuel Consumption Compared under Similar Cabin Comfort: In this first set of simulations, the four controllers are tuned to have similar thermal performance in order to compare the fuel consumption. The threshold of the thermostat controller $T_{h}$ is set as $0.5^{\circ} \mathrm{C}$, the PMV reference is null, control gains are set $K_{p}=1, K_{i}=0.05, K_{e}=1$ and the efficiency threshold in (8) is $\eta_{t}=0.8$, while the threshold in (9) has been set to $\bar{\eta}_{t}=0.15$ to take into account an average $C O P$ of 5 .

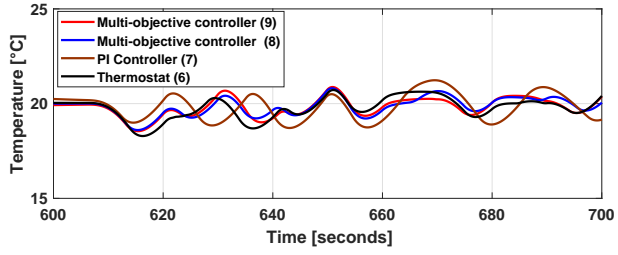

Figure 3: The cabin temperature, PMV, switching signal under different $\mathrm{A} / \mathrm{C}$ control schemes against the engine speed.

As shown in Fig. 3, the cabin temperature and the PMV are varied in a similar range for the four different controllers. The mean temperature and PMV are same which is $20^{\circ} \mathrm{C}$ and 0 . In other words, these four controllers give similar performance in term of cabin comfort. However, the fuel consumption differs as shown in Table I. where the fuel consumption of the IC engine under the different $\mathrm{A} / \mathrm{C}$ control schemes is presented. It is interesting to note that the two proposed multi-objective controllers (8) and (9) have the same fuel consumption.

Table I: Fuel consumption of different control methods (WLTP)

\begin{tabular}{|l|l|c|c|}
\hline Methods & Fuel Usage & $\begin{array}{c}\text { A/C Fuel } \\
\text { Usage }\end{array}$ & $\begin{array}{c}\text { A/C Fuel } \\
\text { Saving }\end{array}$ \\
\hline No A/C & $1.344 \mathrm{~kg}$ & Baseline & \\
\hline Thermostat 6 & $1.586 \mathrm{~kg}$ & $0.242 \mathrm{~kg}$ & $0 \%$ \\
\hline PI controller (7) & $1.581 \mathrm{~kg}$ & $0.237 \mathrm{~kg}$ & $2.10 \%$ \\
\hline Multi-objective controller $[8$ & $1.576 \mathrm{~kg}$ & $0.232 \mathrm{~kg}$ & $4.31 \%$ \\
\hline Multi-objective controller [9] & $1.576 \mathrm{~kg}$ & $0.232 \mathrm{~kg}$ & $4.31 \%$ \\
\hline
\end{tabular}

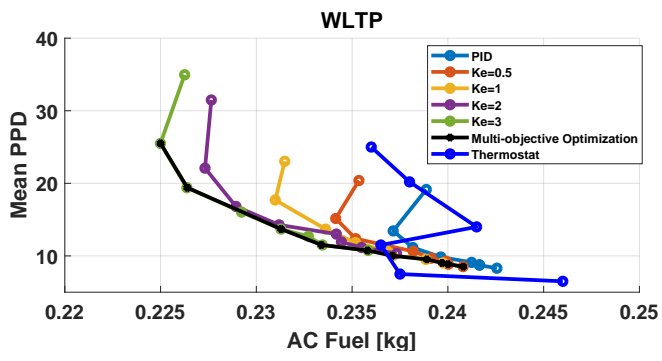

Figure 4: The mean PPD against the A/C system fuel consumption when tracking WLTP driving cycle

2) Optimization of the Proposed Multi-objective Controllers: From the concept of thermal comfort, people will hardly notice the temperature change if the thermal comfort is maintained within the neutral zone. In practice, the closed environment is considered as comfortable if the PMV is between -0.5 and $+0.5[11]$. Hence, it is meaningful to investigate the relationship between the cabin comfort and fuel consumption. For convenience, the mean PPD value is used to indicate the mean discomfort in the cabin during the whole simulation. For the PI controllers (7) and the two proposed multi-objective controllers (8) (9), the temperature and PMV vary in a larger range with the same mean value when decreasing $K_{p}$ or increasing $K_{e}$. For the thermostatic controller, the variation of the temperature and PMV will increase when increasing the temperature threshold $T_{h}$.

In order to make a fair comparison of these controllers, multi-objective optimization, which makes a compromise be- 
tween cabin comfort and $\mathrm{AC}$ fuel consumption, has been carried out. It should be mentioned that as the performance of the two multi-objective controllers is very similar. In the following part, only the results of controller 9 is displayed. And the PI controller has been treated as a special case of the proposed multi-objective controllers with $K_{e}=0$. As shown in Fig. 4, each line (except the black line) indicates the relationship between the mean PPD and the A/C system fuel consumption for a fixed $K_{e}$ and varied $K_{p}$. Then the black line is the Pareto frontier after multi-objective optimization. As we can see, for the PI controller (7) and multi-objective controller (9), the A/C system fuel consumption decreases when the mean PPD increases. For the thermostat this relationship is not convex. On the other hand, for a given mean PPD value the $\mathrm{A} / \mathrm{C}$ fuel usage is always minimised when the $\mathrm{A} / \mathrm{C}$ system is controlled by the multi-objective controller 9 ).

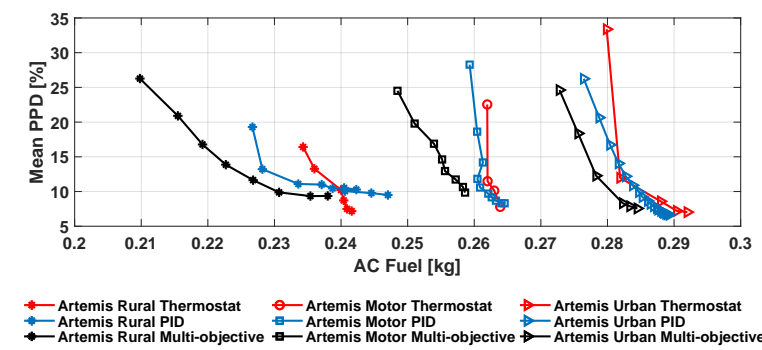

Figure 5: The mean PPD against the A/C system fuel consumption when tracking Artemis cycles

\section{B. A/C System Performance Under Different Driving Cycles}

In this subsection, the vehicle speed is controlled to track three different driving cycles [18]: the urban, rural and highway Artemis cycles. A similar simulation procedure has been carried out as in subsection A above. The parameters $K_{P}$, $K_{e}$, and $T_{h}$ have been changed in each set of simulations to investigate the relationship between the mean PPD and the A/C system fuel consumption. As shown in Fig. 5, the fuel consumption under the modified PI controller (9) is always the minimum among the three controllers for a given driving cycle. Hence, we can claim that by introducing the term $K_{e}\left(\eta_{e}-\eta_{t}\right)$, the controller (9) can give an trade-off between the thermal performance and fuel consumption.

\section{CONCLUSION}

In this paper, the cabin thermal comfort and energy management of $\mathrm{A} / \mathrm{C}$ systems of passenger cars has been studied. In order to simultaneously maintain a high thermal comfort in the cabin and reduce $\mathrm{A} / \mathrm{C}$ system fuel consumption, a multiobjective controller is proposed, which is formulated as a multi-input, single-output, PI controller. To test the performance of the controller, the A/C system model, cabin thermal model and vehicle model are also presented. Simulations were carried out to compare the proposed controller with two stateof-the-art controllers: thermostat control and traditional PI control under several different driving cycles. It is shown by the simulation results that the fuel consumption of the proposed controller is the minimum among several controllers with similar thermal performance. Despite its enhanced performance, the proposed controller requires only a table lookup of engine efficiency compared to the corresponding PI controller. Importantly, if engine torque and RPM are obtained from the engine ECU, no additional sensors are required compared to existing approaches .

\section{ACKNOWLEDGMENT}

This work was supported by the Engineering and Physical Sciences Research Council (EPRSC) [grant number: EP/N022262/1].

\section{REFERENCES}

[1] V. H. Johnson, "Fuel used for vehicle air conditioning: a state-by-state thermal comfort-based approach," SAE Technical Paper, Tech. Rep., 2002.

[2] M. Lambert and B. Jones, "Automotive adsorption air conditioner powered by exhaust heat. part 1: conceptual and embodiment design," Proceedings of the Institution of Mechanical Engineers, Part D: Journal of Automobile Engineering, vol. 220, no. 7, pp. 959-972, 2006.

[3] R. W. Haines and D. C. Hittle, Control systems for heating, ventilating, and air conditioning. Springer Science \& Business Media, 2006.

[4] B. Li and A. G. Alleyne, "Optimal on-off control of an air conditioning and refrigeration system," in American Control Conference (ACC), 2010. IEEE, 2010, pp. 5892-5897.

[5] H. Deng, L. Larsen, J. Stoustrup, and H. Rasmussen, "Control of systems with costs related to switching: applications to air-condition systems," in Control Applications,(CCA) \& Intelligent Control,(ISIC), 2009 IEEE. IEEE, 2009, pp. 554-559.

[6] J. Liu, H. Zhou, X. Zhou, Y. Cao, and H. Zhao, "Automative air conditioning system control-a survey," in Electronic and Mechanical Engineering and Information Technology (EMEIT), 2011 International Conference on, vol. 7. IEEE, 2011, pp. 3408-3412.

[7] B. C. Ng, I. Z. M. Darus, H. Jamaluddin, and H. M. Kamar, "Dynamic modelling of an automotive variable speed air conditioning system using nonlinear autoregressive exogenous neural networks," Applied Thermal Engineering, vol. 73, no. 1, pp. 1255-1269, 2014.

[8] H. Khayyam, J. Abawajy, and R. N. Jazar, "Intelligent energy management control of vehicle air conditioning system coupled with engine," Applied thermal engineering, vol. 48, pp. 211-224, 2012.

[9] Y. Farzaneh and A. A. Tootoonchi, "Controlling automobile thermal comfort using optimized fuzzy controller," Applied Thermal Engineering, vol. 28, no. 14, pp. 1906-1917, 2008.

[10] Q. Zhang, S. Stockar, and M. Canova, "Energy-optimal control of an automotive air conditioning system for ancillary load reduction," in Automotive Air Conditioning. Springer, 2016, pp. 217-245.

[11] R. J. De Dear and G. S. Brager, "Thermal comfort in naturally ventilated buildings: revisions to ashrae standard 55," Energy and buildings, vol. 34, no. 6, pp. 549-561, 2002.

[12] P. O. Fanger et al., "Thermal comfort. analysis and applications in environmental engineering." Thermal comfort. Analysis and applications in environmental engineering., 1970.

[13] DuPont. Thermodynamic properties of HFC-134a refrigerant. [Online]. Available: https://www.chemours.com/Refrigerants/en_US/ assets/downloads/h47751_hfc134a_thermo_prop_eng.pdf

[14] M. Iqbal, An introduction to solar radiation. Elsevier, 2012

[15] Y. Oh, J. Park, J. Lee, M. Do Eom, and S. Park, "Modeling effects of vehicle specifications on fuel economy based on engine fuel consumption map and vehicle dynamics," Transportation Research Part D: Transport and Environment, vol. 32, pp. 287-302, 2014.

[16] H. M. Pham, A. Singh, J.-L. M. Caillat, and M. Bass, "Adaptive control for a refrigeration system using pulse width modulated duty cycle scroll compressor," Apr. 11 2000, uS Patent 6,047,557.

[17] P. Mock, J. Kühlwein, U. Tietge, V. Franco, A. Bandivadekar, and J. German, "The WLTP: How a new test procedure for cars will affect fuel consumption values in the EU," International Council on Clean Transportation, 2014.

[18] M. André, "The artemis european driving cycles for measuring car pollutant emissions," Science of the total Environment, vol. 334, pp. 73-84, 2004. 